Article

\title{
Rapid One-Pot Synthesis of Polydopamine Encapsulated Carbon Anchored with Au Nanoparticles: Versatile Electrocatalysts for Chloramphenicol and Folic Acid Sensors
}

\author{
Veerappan Mani *, T.S.T. Balamurugan $(1)$ and Sheng-Tung Huang * \\ Institute of Biochemical and Biomedical Engineering, Department of Chemical Engineering and Biotechnology, \\ National Taipei University of Technology, No.1, Section 3, Chung-Hsiao East Road, Taipei 10608, Taiwan \\ * Correspondence: veera.678@gmail.com (V.M.); ws75624@ntut.edu.tw (S.-T.H.); \\ Tel.: +886-2271-2171-2525 (V.M. \& S.-T.H.); Fax: +886-02-2731-7117 (S.-T.H.)
}

Received: 24 March 2020; Accepted: 16 April 2020; Published: 19 April 2020

check for updates

\begin{abstract}
Designing and engineering nanocomposites with tailored physiochemical properties through teaming distinct components is a straightforward strategy to yield multifunctional materials. Here, we describe a rapid, economical, and green one-pot microwave synthetic procedure for the preparation of ternary nanocomposites carbon/polydopamine/Au nanoparticles (C/PDA/AuNPs; $\mathrm{C}=$ carbon nanotubes (CNTs), reduced graphene oxide (rGO)). No harsh reaction conditions were used in the method, as are used in conventional hydrothermal or high-temperature methods. The PDA unit acts as a non-covalent functionalizing agent for carbon, through $\pi$ stacking interactions, and also as a stabilizing agent for the formation of AuNPs. The CNTs/PDA/AuNPs modified electrode exhibited excellent electrocatalytic activity to oxidize chloramphenicol and the resulting sensor exhibited a low detection limit $(36 \mathrm{nM})$, wide linear range $(0.1-534 \mu \mathrm{M})$, good selectivity (against 5 -fold excess levels of interferences), appreciable reproducibility (3.47\%), good stability $(94.7 \%)$, and practicality (recoveries $95.0 \%-98.4 \%$ ). Likewise, rGO/PDA/AuNPs was used to fabricate a sensitive folic acid sensor, which exhibits excellent analytical parameters, including wide linear range (0.1-905 $\mu \mathrm{M})$ and low detection limit $(25 \mathrm{nM})$. The described synthetic route includes fast reaction time (5 $\mathrm{min}$ ) and a readily available household microwave heating device, which has the potential to significantly contribute to the current state of the field.
\end{abstract}

Keywords: biopolymer; green synthesis; electroanalysis; electrocatalytic sensor; vitamins; antibiotics

\section{Introduction}

Nano architectures hold a significant role in modern technology, with a wide range of applications in clinical diagnosis, drug delivery, catalysis, energy storage, and electroanalytical science [1-3]. This wide array of utilities is made possible by tailoring the physiochemical properties of nanostructures, which can be done by coupling two or more nanostructures to engineer a fruitful nanocomposite with the desired physiochemical properties [4,5]. Designing and engineering nanocomposites with tailor-made physiochemical properties through teaming distinct nanocomponents results in enhanced mechanical strength, abundant surface area, high charge storage capacity, improved electrical conductivity, improved stability, biocompatibility, and elevated electrocatalytic performance [6-8]. Carbon nanostructures have become well known over the years thanks to their unique structures, good chemical stability, high aspect ratio, low density, and excellent electronic, thermal, and mechanical behaviors [9]. Despite these unique physiochemical attributes, pristine carbon nanostructures like graphene and carbon nanotubes (CNTs) are not easy to access in a wide range of applications [10]. 
Thus, tailoring the carbon materials via functionalization has become essential in order to refine their electronic properties for a desired application [6,11]. Interestingly, carbon nanomaterials are easy to be functionalized and act as a fruitful supporting backbone for metals and metal oxides $[12,13]$. This property enables a range of possibilities to design carbon nanomaterials functionalized and/or anchored with various nanostructures aimed at specific applications [14]. Carbon materials bound with polymers and/or metal nanoparticles were applied distinctly for various applications like batteries, supercapacitors, and electrocatalysis [15]. The polymer functionalization of carbon materials has derived considerable attention due to the fact of their uniform encapsulation/functionalization over the surface of carbon backbone and offers additional active sites for catalysis and secondary functionalization [15]. Added to this, calcination of heterotopic polymer-functionalized carbon materials offers a unique entrapment of heterotopic graphene sheet over primary carbon backbone with abundant active sites and improved catalytic attributes [16]. Polydopamine (PDA) is a key bio-mimic polymer employed to functionalize carbon materials, courtesy of its excellent biocompatibility, uniform entrapment on the surface, controllable polymerization thickness, abundant functional groups for catalysis, and secondary functionalization options [15]. PDA coating can be easily prepared by self-polymerization of dopamine at alkaline $\mathrm{pH}$, and this coating can be used to immobilize a wide variety of molecules, such as active metal nanoparticles [17]. The polymerization is a quick process and the coating thickness can be controlled by polymerization time. Metal nanoparticles have become widely known over the years and are employed in a broad range of utilities in electroanalysis $[18,19]$. The inherent physicochemical attributes along with the excellent synergy on blending with carbon nanostructures with customized physiochemical assets for specific functions has elevated their real time utilities vividly over the years [20]. The idea of ternary carbon nanocomposites derived from primarily functionalized carbon nanostructures are an evolutionary sequence to design carbon nanomaterials with customized physiochemical attributes for a definite function $[13,21]$. The polymer enwrapped carbon nanostructures anchored with metal nanoparticles is an effective way to tailor the physiochemical attributes of the nanostructures for specific applications, as the composites have the synergic blend of the all three constituents [19]. The design of carbon enwrapped PDA bounded with metal nanostructures (C/PDA/MNP) are of recent interest due to its wide array of applications in diverse areas of analytical chemistry. For instance, Li et al. prepared CNTs/PDA/gold nanoparticles (AuNPs) as an electrocatalyst for simultaneous detection of catechol and hydroquinone [22]. Liu et al. designed Ag-PDA/graphene as an electrocatalyst to assay adenine and guanine [23]. Wang et al. constructed a DNA biosensor using AgNPs-PDA/graphene as an electrocatalyst [24]. Liang et al. reported a hydrogen peroxide sensor based on graphene oxide (GO)/PDA/Cu NPs electrode [25]. Yao et al. employed AuNPs-PDA-reduced GO catalyst to build an immunosensor to quantify immunoglobulin G [26]. Despite their strong electrocatalytic proficiency, the design and preparations of such ternary nanocomposites are quite troublesome as it involves multiples steps, harsh reagents, use of high pressure or temperature, and prolonged reaction time [24].

In this study, we are proposing an alternate microwave-assisted green synthetic protocol to prepare PDA-encapsulated carbon nanomaterials anchored with AuNPs. The synthesis involves a rapid one-step polymerization of PDA over carbon nanomaterials followed by a growth of AuNPs over PDA enwrapped carbon backbone (Scheme 1). Efficacy of the synthetic route has been demonstrated via preparing a pair of electrocatalysts, (1) CNTs/PDA/AuNPs and (2) rGO/PDA/AuNPs; Here $\mathrm{PDA}=$ Polydopamine, $\mathrm{rGO}=$ reduced graphene oxide. Both the nanocomposites have excellent surface properties, porous structures, high conductivity, large electrochemical surface area, and excellent electrocatalytic abilities. The main advantages of the method are fast reaction time and the use of a readily available household microwave heating device. The physicochemical properties of the $\mathrm{CNTs} / \mathrm{PDA} / \mathrm{AuNPs}$ and $\mathrm{rGO} / \mathrm{PDA} / \mathrm{AuNPs}$ nanocomposites have been used to fabricate electrochemical sensors for chloramphenicol (CAP) and folic acid (FA), respectively. Chloramphenicol is a veterinary antibacterial drug commonly used to treat infectious diseases in food-producing animals [27,28]. However, its excess level is associated with serious toxic effects such as bone marrow depression and 
its absorption in human beings is rapid and extensive after an oral dose [29-31]. Hence, its quantitative determination in foods that originate from poultry is essential. Electrochemical sensors are robust, inexpensive, portable, and easy to operate [32]. Here, we have developed a sensitive CAP sensor using the CNTs/PDA/AuNPs nanocomposite-modified electrode. Folic acid (FA) is a B-group vitamin that plays a significant role in the biological functions of cell metabolism $[33,34]$. Its deficiency in our body causes many disorders, including increased risk of colorectal cancer, neural tube defects, hypomethylation, and triggering proto-oncogene expression in cancer [35-37]. Supplements in different quantities of FA are available to treat FA deficiency and hence its quantitative determination is necessary to control the quality of pharmaceutical and food products. Using the rGO/PDA/AuNPs nanocomposite, here, we have developed a handy and affordable electrochemical sensor for detecting FA in food samples.

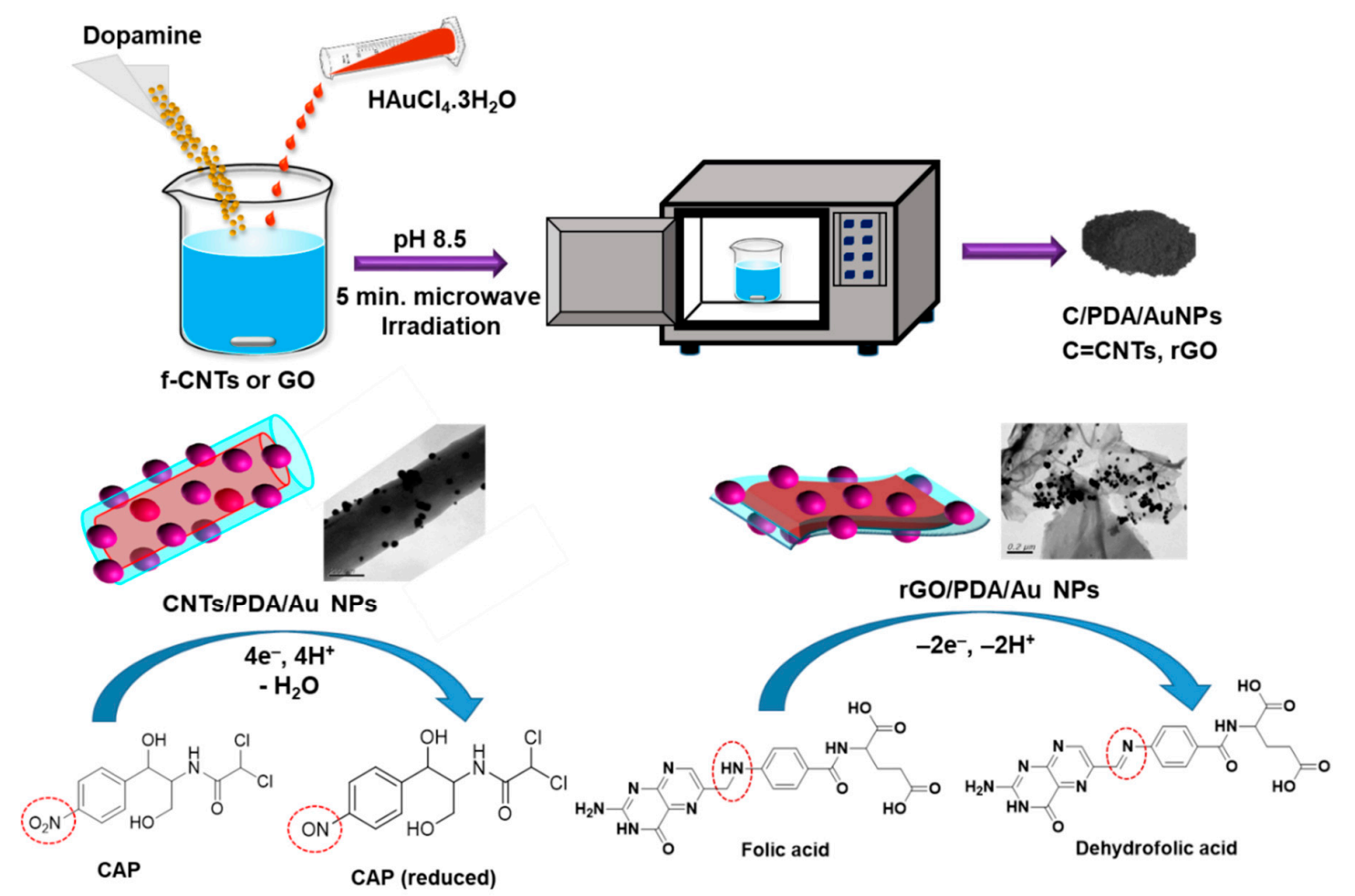

Scheme 1. Schematic representation for rapid synthesis of $C / P D A / A u N P s ; C=C N T s \&$ rGO, PDA = Polydopamine, AuNPs = Gold nanoparticles (top). (bottom) Structural architecture and TEM images of the composites.

\section{Results and Discussion}

\subsection{The Morphology, Structure, and Composition of CNTs/PDA/AuNPs}

The morphology of the materials was assessed by SEM and TEM analyses. The SEM micrograph of CNTs/PDA displays the characteristic tubular morphology of CNTs; however, the PDA coating is not clearly visible (Figure 1A). The image of CNTs/PDA/AuNPs reveals the attachment of a large number of spherical particles in the hierarchal interconnected networks of CNTs/PDA (Figure 1B). The formation of nanoparticles is apparent from the higher magnification SEM as the particle sizes are in the nanometer scale (Figure 1C). The morphology of the composite was further viewed by TEM at different magnifications, which clearly revealed the distribution of minute nanosized spherical AuNPs on the surface of CNTs/PDA (Figure 1D,E). No particle is dispersed outside the matrix of CNTs/PDA. In the TEM image, the coatings of PDA appear as non-smooth coatings on the walls of CNTs. The appearance of AuNPs attachment indicates that the growth of each particle has originated from the PDA layer, thus PDA is an appropriate stabilizing agent for AuNPs. The EDX profile of 
$\mathrm{CNTs} / \mathrm{PDA} / \mathrm{AuNPs}$ reveals the signals of expected elements, $\mathrm{C}, \mathrm{N}, \mathrm{O}$, and $\mathrm{Au}$ (Figure 1F), with atomic percentages of $79.54 \%, 9.42 \%, 10.5 \%$, and $0.54 \%$, and weight percentages of $71.14 \%, 9.83 \%, 12.63 \%$, and $6.4 \%$, respectively.

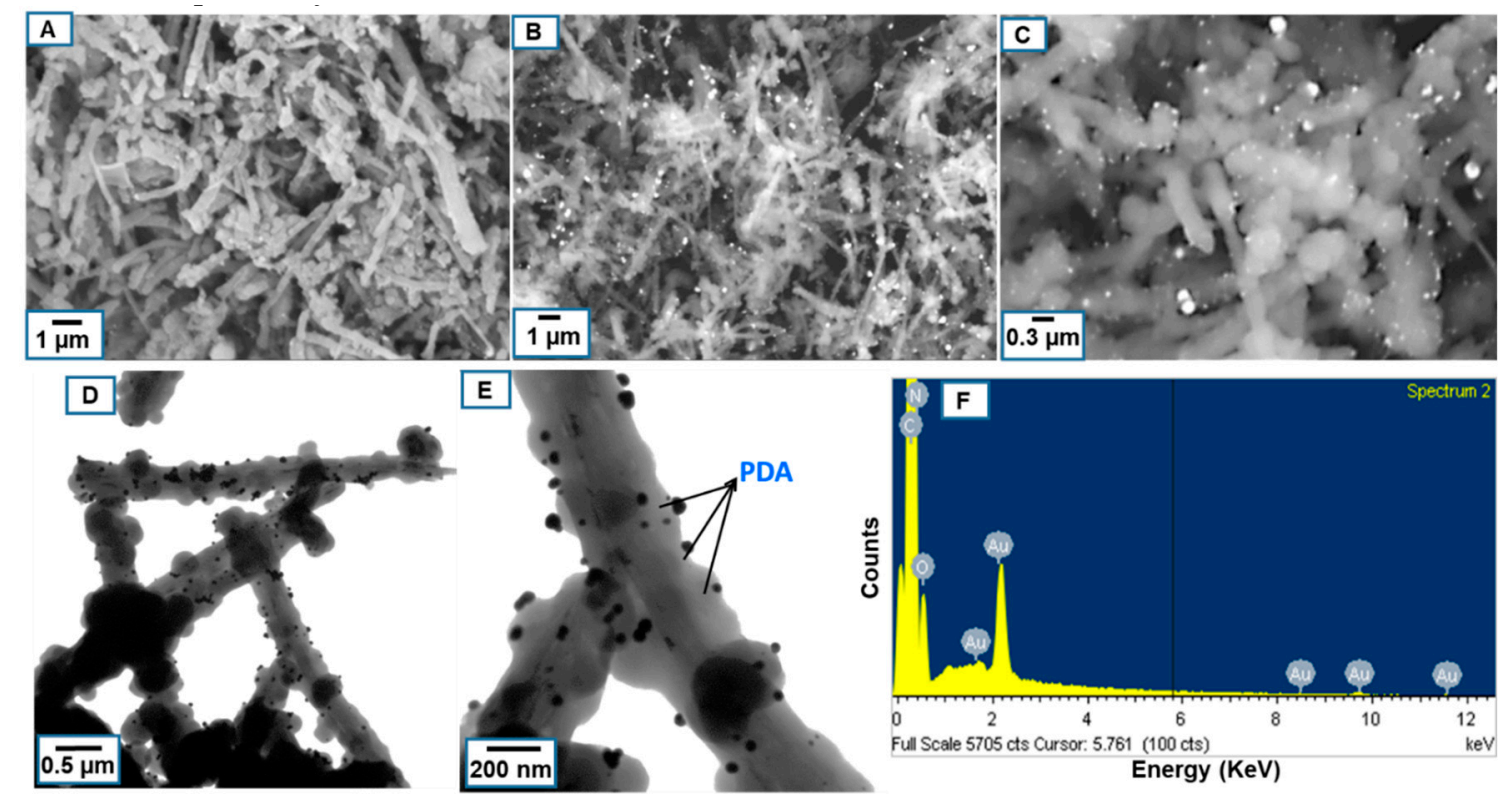

Figure 1. (A) SEM images of CNTs/PDA and CNTs/PDA/AuNPs at (B) lower and (C) higher magnifications.

(D,E) TEM image of CNTs/PDA/AuNPs at different magnifications. (F) EDX spectrum of CNTs/PDA/AuNPs.

Figure 2A displays the powder XRD patterns of the CNTs/PDA/AuNPs. The diffraction peak that appeared at the $2 \theta$ angle of 26.2 can be assigned to the hexagonal crystalline graphite. The diffraction peaks observed at 38.7, 44.5, 64.8, and 77.8 can be allocated to $\mathrm{Au}(111),(200),(220)$, and (311) respectively, which confirms the presence of AuNPs in the composite [38,39]. Next, the surface chemical compositions were investigated using XPS (Figure 2B). The XPS spectrum of CNTs/ PDA/AuNPs displayed the characteristic XPS signals at the binding energies of 85.6, 89.2, 286.2, 401.4, and $533.7 \mathrm{eV}$. The peaks appearing at 85.6 and $89.2 \mathrm{eV}$ were corresponding to the $4 \mathrm{f} 5 / 2$ and $4 \mathrm{f} 7 / 2$ spin-orbit split components, characteristic of the presence of the Au element in the composite (Figure 2C). The XPS signal originating at $286.2 \mathrm{eV}$ can be associated with the $\mathrm{C} 1 \mathrm{~s}$ mode, which originates from the graphitic network of reduced graphene oxide (Figure 2D). The XPS peak which appeared at 401.4 matches with the XPS signature of N1s (Figure 2E). The signal observed at $532.5 \mathrm{eV}$ can be correlated to the $\mathrm{O} 1 \mathrm{~s}$ that originated from the PDA and to the residual oxygen functionalities incorporated in the rGO sheets (Figure 2F).

\subsection{Characterizations of $r G O / P D A / A u N P s$}

Next, the formation of the rGO/PDA/AuNPs nanocomposite was verified by characterization studies. The SEM micrograph of rGO portrays a characteristic wrinkled sheets-like morphology of rGO (Figure 3A). The coating of PDA in layers of rGO sheets is not clear in the SEM of rGO/PDA, which could be due to the poor conducting property of PDA (Figure 3B). However, the presence of abundant AuNPs onto the sheets is evident in the SEM of rGO/PDA/AuNPs (Figure 3C). The TEM images of $\mathrm{rGO} / \mathrm{PDA} / \mathrm{AuNPs}$ at different magnifications revealed the distribution of the nanosized $\mathrm{Au}$ particles on the rGO/PDA sheets (Figure 3D,E). The EDX profile of $\mathrm{rGO} / \mathrm{PDA} / \mathrm{AuNPs}$ shows the elements $\mathrm{C}, \mathrm{O}, \mathrm{N}$, and $\mathrm{Au}$ (Figure $3 \mathrm{~F}$ ), with atomic percentages of $69.70 \%, 23.33 \%, 6.35 \%$, and $0.62 \%$, and weight percentages of $66.81 \%, 24.29 \%, 6.24 \%$, and $2.66 \%$, respectively. 

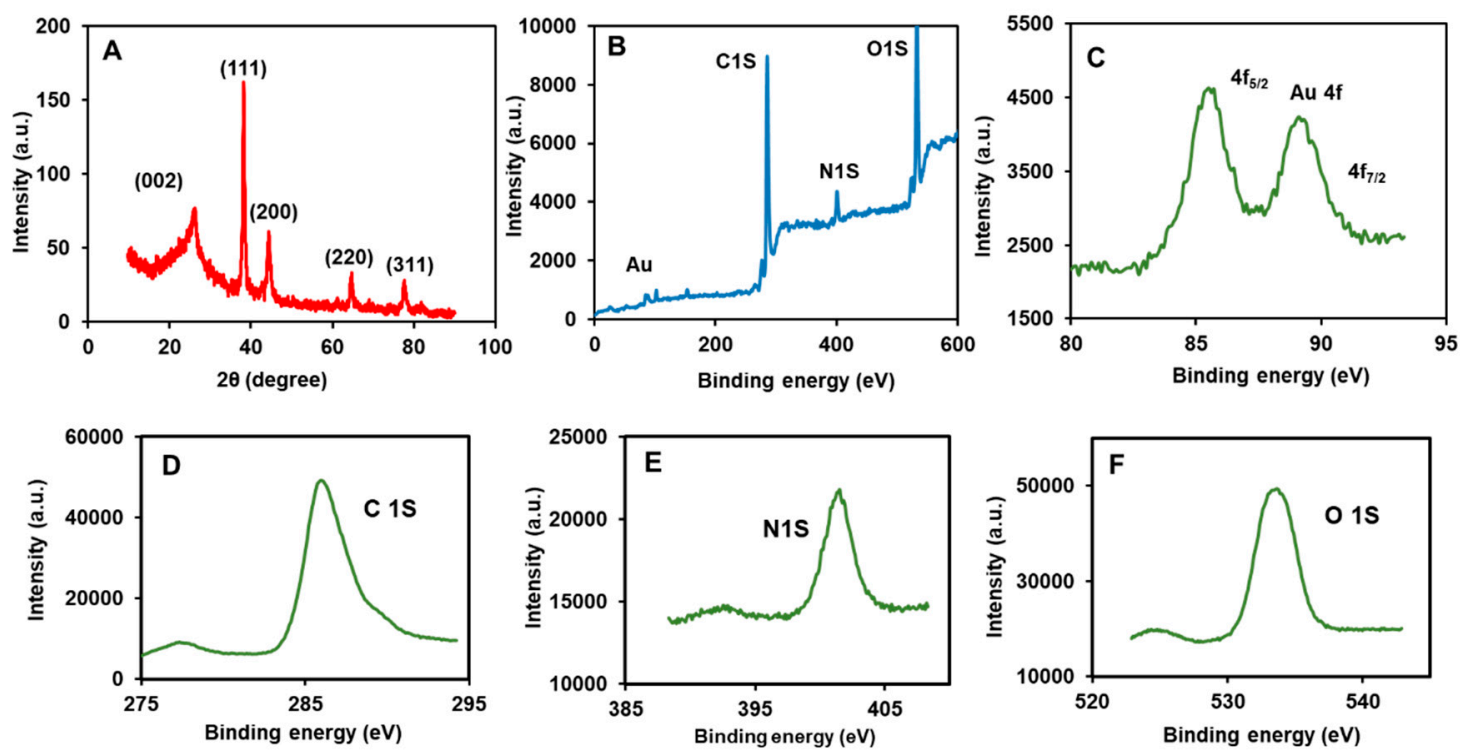

Figure 2. (A) X-ray diffraction patterns, (B) X-ray photoelectron spectroscopy (XPS) survey spectrum, and $(\mathbf{C}-\mathbf{F})$ XPS relevant to each atom of the CNTs/PDA/AuNPs nanocomposite.

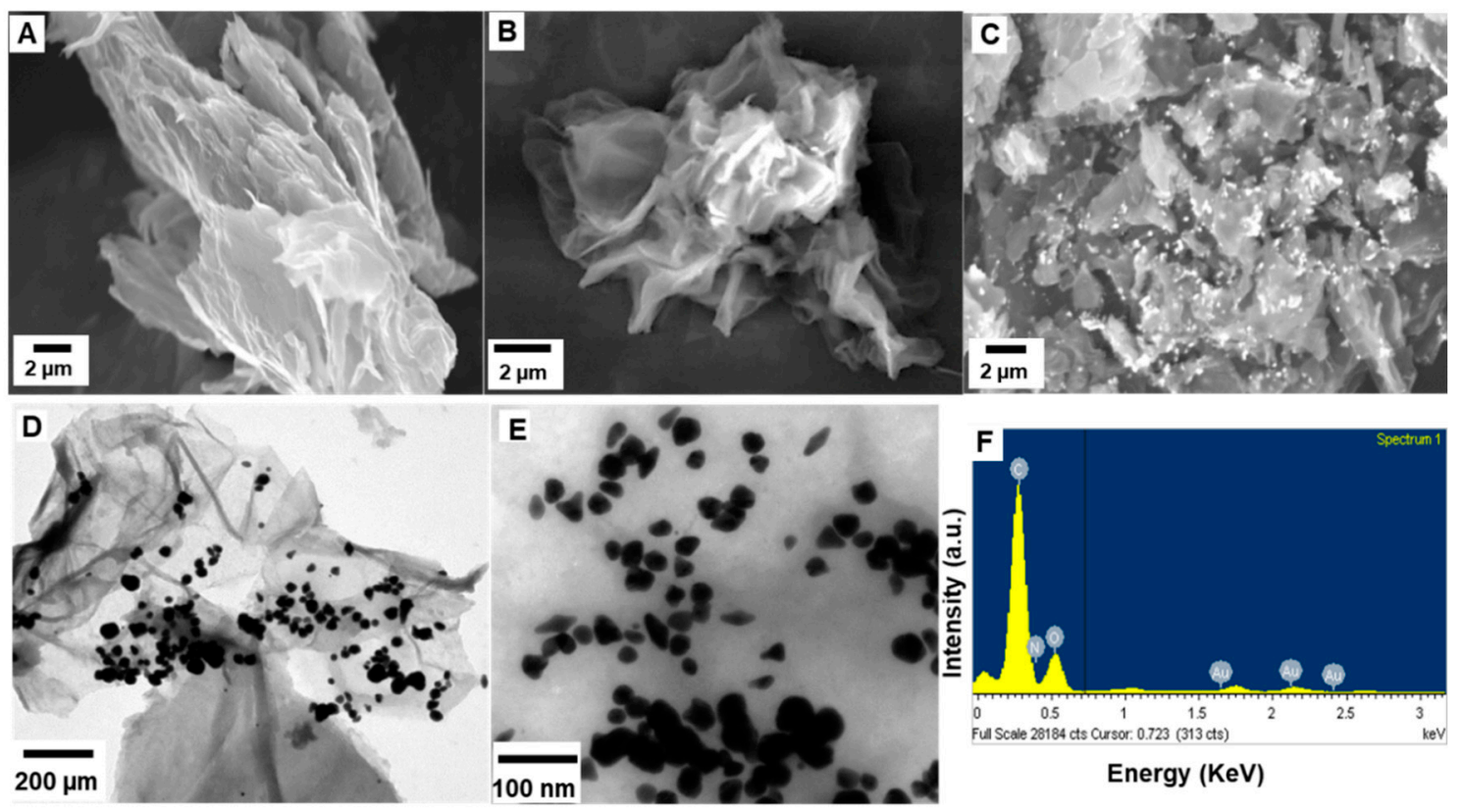

Figure 3. (A) SEM images of $\mathrm{rGO}$, (B) rGO/PDA, and (C) rGO/PDA/AuNPs. (D,E) TEM images of rGO/PDA/AuNPs at different magnifications. (F) EDX spectrum of rGO/PDA/AuNPs.

Figure $4 \mathrm{~A}$ shows the XRD profile of the rGO/PDA/AuNPs. The diffraction peak at 25.1 is assigned to the graphite structure of rGO, and the signals at 38.4 (111), 44.1(200), 64.7 (220), and 77.2 (311) correspond to the pattern of AuNPs [40]. The XPS spectrum of rGO/PDA/AuNPs displayed the characteristic signals at 83.2, 87.3, 284.8, 400.2, and $532.6 \mathrm{eV}$ (Figure $4 \mathrm{~B}$ ). The $4 \mathrm{f}_{/ 2}$ and $4 \mathrm{f} 7_{/ 2}$ spin-orbit split components at 83.2 and $87.3 \mathrm{eV}$ respectively, indicate the presence of $\mathrm{Au}$ (Figure 4C). A signal at $284.8 \mathrm{eV}$ is identified as a C 1s mode, originating from the graphitic network of the rGO (Figure 4D). A signal at $400.2 \mathrm{eV}$ relates N1s (Figure $4 \mathrm{E}$ ) and a signal at $532.6 \mathrm{eV}$ relates $\mathrm{O} 1 \mathrm{~s}$, which originates from PDA (Figure 4F). 

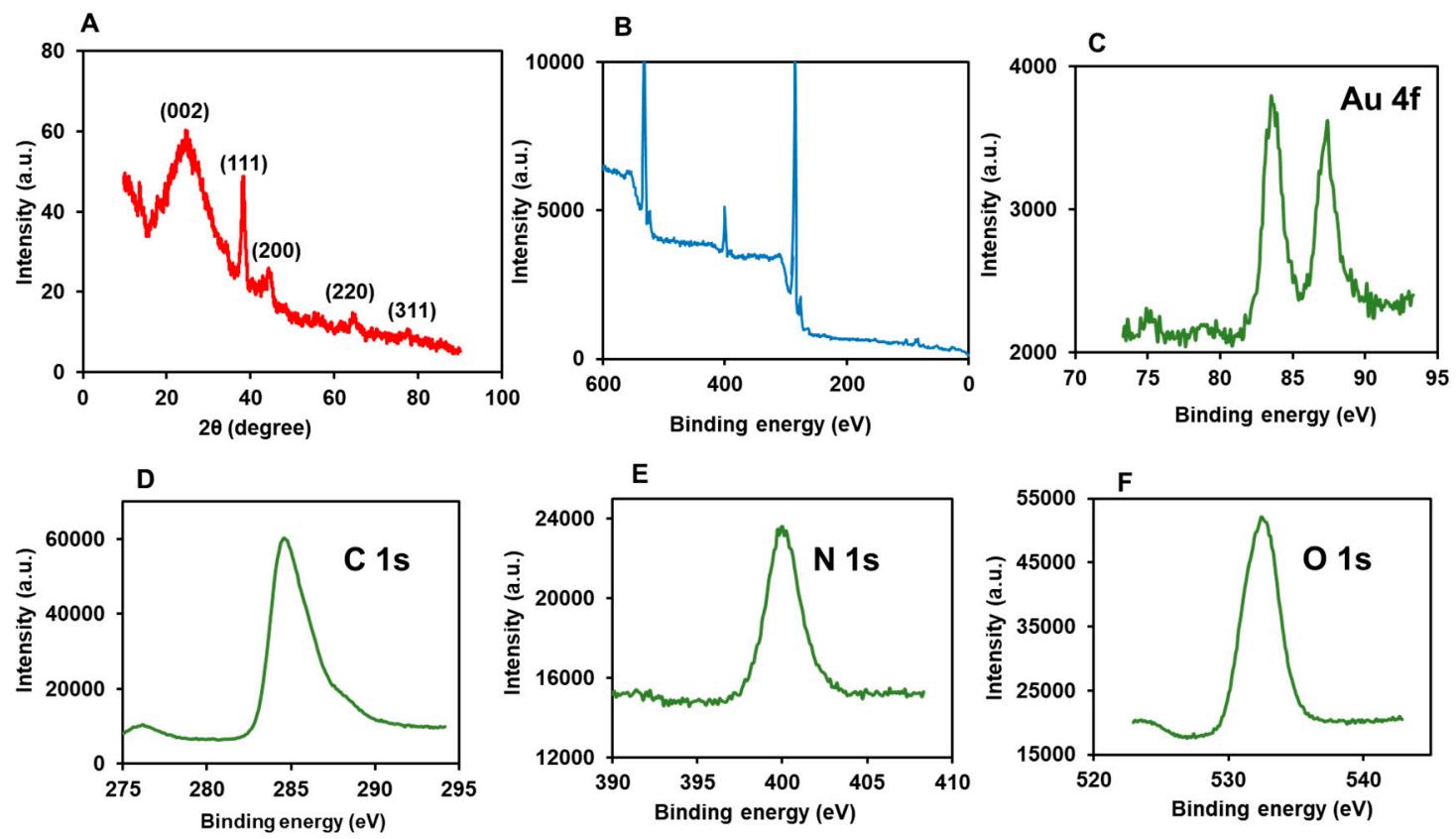

Figure 4. (A) XRD, (B) XPS survey, and (C-F) XPS relevant to atoms of the rGO/PDA/AuNPs composite.

\subsection{Electrocatalytic Sensing Ability of the CNTs/PDA/AuNPs-Modified Electrode to Chloramphenicol}

The electrocatalytic activities of GCE/CNTs/PDA/AuNPs and its control electrodes have been studied by voltammetry (Figure 5A). Here, GCE = glassy carbon electrode. The cathodic peak current $\left(I_{\mathrm{pc}}\right)$ responsible for CAP reduction is found to be 13.4, 5.3, and 2 times higher than that obtained at unmodified, GCE/PDA/CNTs, and GCE/CNTs/AuNPs, respectively (inset to Figure 5A). The main cathodic peak is corresponding to the electrocatalytic reduction of the $\mathrm{NO}_{2}$ group of CAP to NHOH (hydroxyl) [41]. The $\mathrm{NHOH}$ can be further oxidized to $\mathrm{NO}$ at positive potentials. At GCE/CNTs/PDA/AuNPs, the overpotential for the CAP reduction reaction is observed $100 \mathrm{mV}$ lower than the unmodified GCE. Improved peak current and decreased overpotential corroborate the superior electrocatalytic aptitude of $\mathrm{CNTs} / \mathrm{PDA} / \mathrm{AuNPs}$ for $\mathrm{CAP}$ reduction. Figure $5 \mathrm{~B}$ presents the voltammetric responses of GCE/CNTs/PDA/AuNPs toward different concentrations of CAP. As the concentration of CAP increased, the $I_{\mathrm{pc}}$ increased linearly, indicating excellent electrocatalysis (inset to Figure $5 \mathrm{~B}$ ). The good linearity also suggests that the electrode does not suffer from fouling. Figure $5 \mathrm{C}$ shows the $\mathrm{CV}$ responses of CNTs/PDA/AuNPs toward $50 \mu \mathrm{M}$ CAP at different scan rates, between 20 and $200 \mathrm{mVs}^{-1}$. The plot between $I_{\mathrm{pc}}$ and the square root of scan rate exhibited good linearity, indicating diffusion-controlled reduction process of CAP (inset to Figure 5C). Figure 5D presents the amperometric signals of the CNTs/PDA/AuNPs-modified electrode upon successive injections of CAP into phosphate buffer ( $\mathrm{pH} 7.0)$ at regular intervals of $50 \mathrm{~s}\left(E_{\mathrm{app}}=-0.70 \mathrm{~V}\right)$. The electrode area is $0.21 \mathrm{~cm}^{2}$ and the rotation speed is $1200 \mathrm{rpm}$. Well-defined and quick responses were obtained immediately after injection of CAP. A steady-state current was reached in five seconds, indicating a rapid response time. A linear increase in the current response was observed as shown in the calibration plot. The corresponding linear regression equation is stated as follows: $I_{\mathrm{pc}}(\mu \mathrm{A})=1.5737 \mathrm{C}(\mu \mathrm{M})$ +26.398 . The linear range was $0.1-534 \mu \mathrm{M}$ and sensitivity was $2.296 \mu \mathrm{A} \mu \mathrm{M}^{-1} \mathrm{~cm}^{-2}$ (Figure 5E). The detection limit (LOD) was $36 \mathrm{nM}$. The sensor parameters are either superior or comparable to the existing modifiers for CAP analysis, as given in Table 1. 

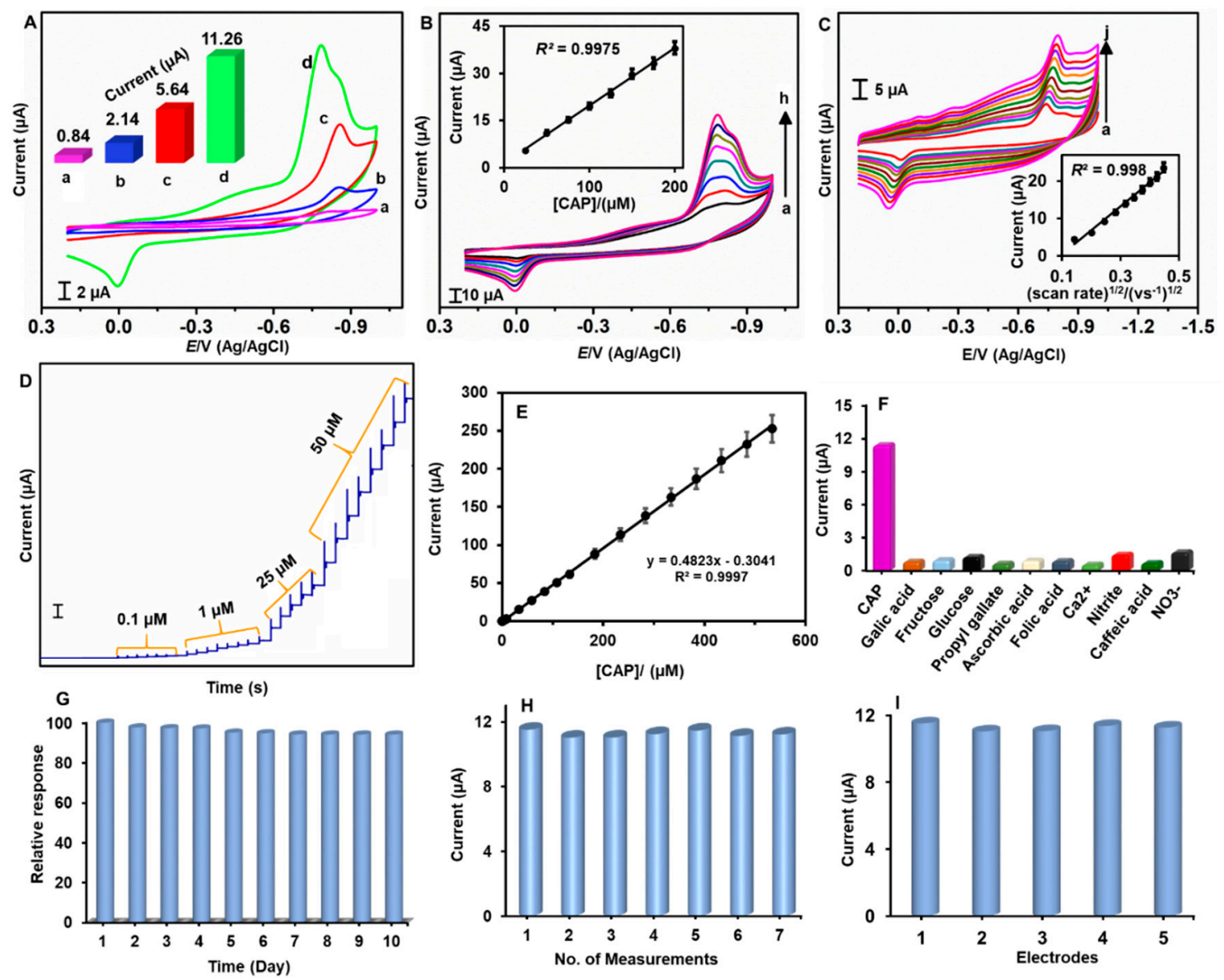

Figure 5. (A) Cyclic voltammograms (CVs) at a scan rate of $0.05 \mathrm{~V} \mathrm{~s}^{-1}$ obtained for (a) unmodified, (b) CNTs/PDA, (c) CNTs/AuNPs, and (d) CNTs/PDA/AuNPs films-modified glassy carbon electrodes (GCEs) in phosphate buffer (pH 7.0) containing $50 \mu \mathrm{M}$ of CAP. (B) CVs of GCE/CNTs/PDA/AuNPs in phosphate buffer ( $\mathrm{pH} 7.0)$ with varied concentrations of CAP $(\mathrm{a}=25, \mathrm{~b}=50, \mathrm{c}=75, \mathrm{~d}=100, \mathrm{e}=125$, $\mathrm{f}=150, \mathrm{~g}=175$, and $\mathrm{h}=200 \mu \mathrm{M})$. Inset: cathodic peak current $/ \mu \mathrm{A}$ versus [CAP] $/ \mu \mathrm{M}$. (C) CVs at different scan rates (a to j: 0.02 to $0.2 \mathrm{~V} \mathrm{~s}^{-1}$ ) of GCE/CNTs/PDA/AuNPs in phosphate buffer (pH 7.0) containing $50 \mu \mathrm{M}$ CAP. Inset: CAP reduction peak current versus (scan rate) ${ }^{1 / 2}$. (D) Amperometric response of GCE/CNTs/PDA/AuNPs to varied amounts of CAP, injected in phosphate buffer ( $\mathrm{pH} 7.0$ ), and (E) corresponding linear calibration plot. (F) Amperometric responses of GCE/CNTs/PDA/AuNPs to $50 \mu \mathrm{M}$ CAP and $0.1 \mathrm{mM}$ of other analytes. (G) CAP sensing performance of GCE/CNTs/PDA/AuNPs for 10 continuous days (stability test), $(\mathbf{H}) 7$ repeated measurements using a single electrode (repeatability test) and (I) reproducibility of 5 separate experiments using 5 separately fabricated electrodes. For stability, repeatability, and reproducibility tests, CVs were performed with $50 \mu \mathrm{M}$ CAP suspended in $0.1 \mathrm{M}$ phosphate buffer ( $\mathrm{pH} 7.0$ ), while CAP reduction peak current was used to plot the bar diagram. 
Table 1. Comparison of analytical parameters for the determination of CAP at CNTs/PDA/AuNPs nanocomposite film with reported modifiers.

\begin{tabular}{ccccc}
\hline Electrode & $\begin{array}{c}\text { Linear } \\
\text { Range/ } \mu \mathbf{M}\end{array}$ & LOD/nM & Methods & Ref. \\
\hline 3D reduced GO & $1-113$ & 150 & $\begin{array}{c}\text { Differential } \\
\text { pulse } \\
\text { voltammetry }\end{array}$ & [42] \\
\hline MoS $/$ self-doped polyaniline & $0.1-1000$ & 65 & $\begin{array}{c}\text { Differential } \\
\text { pulse } \\
\text { voltammetry }\end{array}$ & [43] \\
\hline $\mathrm{Fe}_{3} \mathrm{O}_{4}$-carboxymethyl cellulose/Au & $2.5-25$ & 66 & $\begin{array}{c}\text { Square wave } \\
\text { voltammetry }\end{array}$ & [44] \\
\hline AuNPs/GO & $1.5-2.95$ & 250 & Amperometry & [45] \\
\hline Activated carbon fiber & $0.1-10$ & 47 & $\begin{array}{c}\text { Square wave } \\
\text { voltammetry }\end{array}$ & [46] \\
\hline Titanium nitride-rGO & $0.05-100$ & 20 & Voltammetry & [47] \\
\hline N-doped graphene/AuNPs & $2-80$ & 59 & $\begin{array}{l}\text { Linear sweep } \\
\text { voltammetry }\end{array}$ & [30] \\
\hline CNTs/PDA/AuNPs & $0.1-534$ & 36 & Amperometry & This work \\
\hline
\end{tabular}

Next, selectivity of the modified electrode was evaluated by monitoring its sensing ability to likely interfering agents. Figure 5F displays the amperometric response of CNTs/PDA/AuNPs to $50 \mu \mathrm{M}$ CAP and $250 \mu \mathrm{M}$ interfering compounds (food additives, biological analytes, and metals). The amperometric experiments were conducted by successive injections of $50 \mu \mathrm{M} \mathrm{CAP}, 250 \mu \mathrm{M}$ of each interfering compounds, and finally, again with $50 \mu \mathrm{MCAP}$ at regular intervals of $50 \mathrm{~s}$. The electrode potential was $-0.70 \mathrm{~V}$ and the electrode rotation speed was $1200 \mathrm{rpm}$. The electrode responded rapidly to CAP; however, it was insensitive to other analytes such as, gallic acid, fructose, glucose, propyl gallate, ascorbic acid, folic acid, $\mathrm{Ca}^{2+}$, and caffeic acid. These results suggest that $\mathrm{CNTs} / \mathrm{PDA} / \mathrm{AuNPs}$ have good specificity for recognizing CAP in the presence of other analytes. Only nitrite and nitrate showed slight interferences; but, their contribution is still less than $5 \%$. The $\pi$-stacking interaction between phenyl moieties of the CNTs/PDA and the CAP may play an important role in dictating the selectivity. Other nitrite compounds that do not own $\pi$ electrons are unable to produce measurable signals. The common biological interfering species such as ascorbic acid and glucose did not show significant interference, because the working potential is away from their oxidization potential region. Next, the durability, repeatability, and reproducibility of the sensor were tested. To assess storage stability, the CV performance of GCE/CNTs/PDA/AuNPs towards CAP $(50 \mu \mathrm{M})$ was monitored every day (Figure 5G). After 10 days of continuous storage, the electrode retained about $94.7 \%$ of its initial response, indicating its good durability. The sensor presented acceptable repeatability with a Relative Standard Deviation (RSD) of $2.85 \%$ for seven subsequent measurements carried out using a single $\mathrm{CNTs} / \mathrm{PDA} /$ AuNPs-modified electrode (Figure 5H). Moreover, the modified electrode retained good reproducibility, as the RSD of five separate measurements on all five electrodes was 3.47\% (Figure 5I). Next, practicality of the sensor was demonstrated in food samples. Milk, powdered milk, and honey samples were prepared by following the procedures given in the experimental section. Amperometry experiments were carried out using GCE/CNTs/PDA/AuNPs in CAP-spiked food samples. The spiked CAP concentrations were 1,5 , and $10 \mu \mathrm{M}$. The added, found, and recovery values are presented in Table 2. For the three food samples tested, the recovery values were $95.0 \%-98.4 \%$. Because the recoveries are in an acceptable range, we concluded that the developed modified electrode has good practical applicability and could be a potential sensor in food safety testing. 
Table 2. Determination of spiked CAP in food samples using CNTs/PDA/AuNPs.

\begin{tabular}{ccccc}
\hline Samples & Added $/ \boldsymbol{\mu M}$ & Found $/ \boldsymbol{\mu M}$ & Recovery/\% & RSD $/ \%$ \\
\hline \multirow{3}{*}{ Milk } & 1 & 0.96 & 96.0 & 2.88 \\
& 5 & 4.92 & 98.4 & 2.93 \\
& 10 & 9.63 & 96.3 & 3.50 \\
\hline \multirow{3}{*}{ Powdered milk } & 1 & 0.97 & 97.0 & 3.92 \\
& 5 & 4.83 & 96.6 & 3.52 \\
Honey & 10 & 9.73 & 97.3 & 2.74 \\
\hline & 1 & 0.95 & 95.0 & 4.11 \\
& 10 & 4.80 & 96.0 & 3.4 \\
& 5 & 9.7 & 97.0 & 3.63 \\
\hline
\end{tabular}

* Relative Standard Deviation (RSD) of three individual measurements.

\section{4. rGO/PDA/AuNPs Modified Electrode: An Excellent Electrocatalyst for Sensing Folic Acid}

Next, the electrocatalytic sensing ability of the rGO/PDA/AuNPs composite has been tested for folic acid (FA). Figure 6A presents the CVs of rGO/PDA/AuNPs and its controls toward $50 \mu \mathrm{M}$ FA. The oxidation peak current $\left(I_{\mathrm{pa}}\right)$ of FA at the rGO/PDA/AuNPs-modified GCE was 17.3-, 2.65-, and 1.53-folds higher than those obtained at the unmodified, rGO/PDA, and $\mathrm{rGO} / \mathrm{AuNPs}$ films-modified electrodes (inset to figure 6A). In addition, compared to unmodified GCE, GCE/rGO/PDA, and GCE/rGO/AuNPs, the rGO/PDA/AuNPs-modified electrode has less overpotential of about 180, 50, and $150 \mathrm{mV}$, respectively. Thus, the improved peak current and lowered overpotential indicate that the $\mathrm{rGO} / \mathrm{PDA} / \mathrm{AuNPs}$ is a good electrocatalyst to oxidize FA. Figure $6 \mathrm{~B}$ shows the linear responses of $\mathrm{GCE} / \mathrm{rGO} / \mathrm{PDA} / \mathrm{AuNPs}$ to increasing concentrations of FA. Figure $6 \mathrm{C}$ presents the voltammetric responses of $50 \mu \mathrm{M}$ FA at different scan rates $\left(0.02-0.2 \mathrm{Vs}^{-1}\right)$. The plot between the anodic peak current and the square root of scan rate exhibited good linearity, suggesting the diffusion-controlled reduction process of FA. Figure $6 \mathrm{D}$ presents the amperometric responses of the rGO/PDA/AuNPs-modified electrode to increasing concentrations of FA. The applied potential was $+0.55 \mathrm{~V}$. Quick responses were obtained within $5 \mathrm{~s}$. A wide linear range, $0.1-905 \mu \mathrm{M}$, was observed with a linear regression equation of, $I_{\mathrm{pc}}(\mu \mathrm{A})=0.19(\mathrm{FA})(\mu \mathrm{M})+1.29, R^{2}=0.999$ (Figure $6 \mathrm{E}$ ). The sensitivity was $2.75 \mu \mathrm{A} \mu \mathrm{M}^{-1} \mathrm{~cm}^{-2}$ and the detection limit was $25 \mathrm{nM}$. The sensor parameters of this electrode were significantly improved compared to existing modified electrodes (Table 3). As shown in Figure 6F, the rGO/PDA/AuNPs is highly selective to FA in the presence of other electroactive analytes. The electrode has good storage stability, as evidenced by the fact that $95.2 \%$ of its initial response is retained after 10 days of its use (Figure 6G). Furthermore, the sensor showed acceptable repeatability with an RSD of $3.15 \%$ for seven repetitive measurements (Figure $6 \mathrm{H}$ ), and an appreciable reproducibility with RSD of $3.37 \%$ for seven individual electrodes (Figure 6I).

Practicality of the FA sensor was demonstrated in human serum and urine samples. First, the serum and urine samples were diluted with phosphate buffer $(\mathrm{pH} 7)$ with a 1:50 ratio. The diluted samples were found to be FA free. Then known amounts of FA ( 5 and $10 \mu \mathrm{M})$ were spiked and analyzed. Amperometry experiments were carried out using GCE/rGO/PDA/AuNPs in FA-spiked biological samples. The added, found, and recovery values are presented in Table 4 . The recovery values are in an acceptable range of $95.2 \%-97.3 \%$, which indicates the potential practicality of the electrode. 

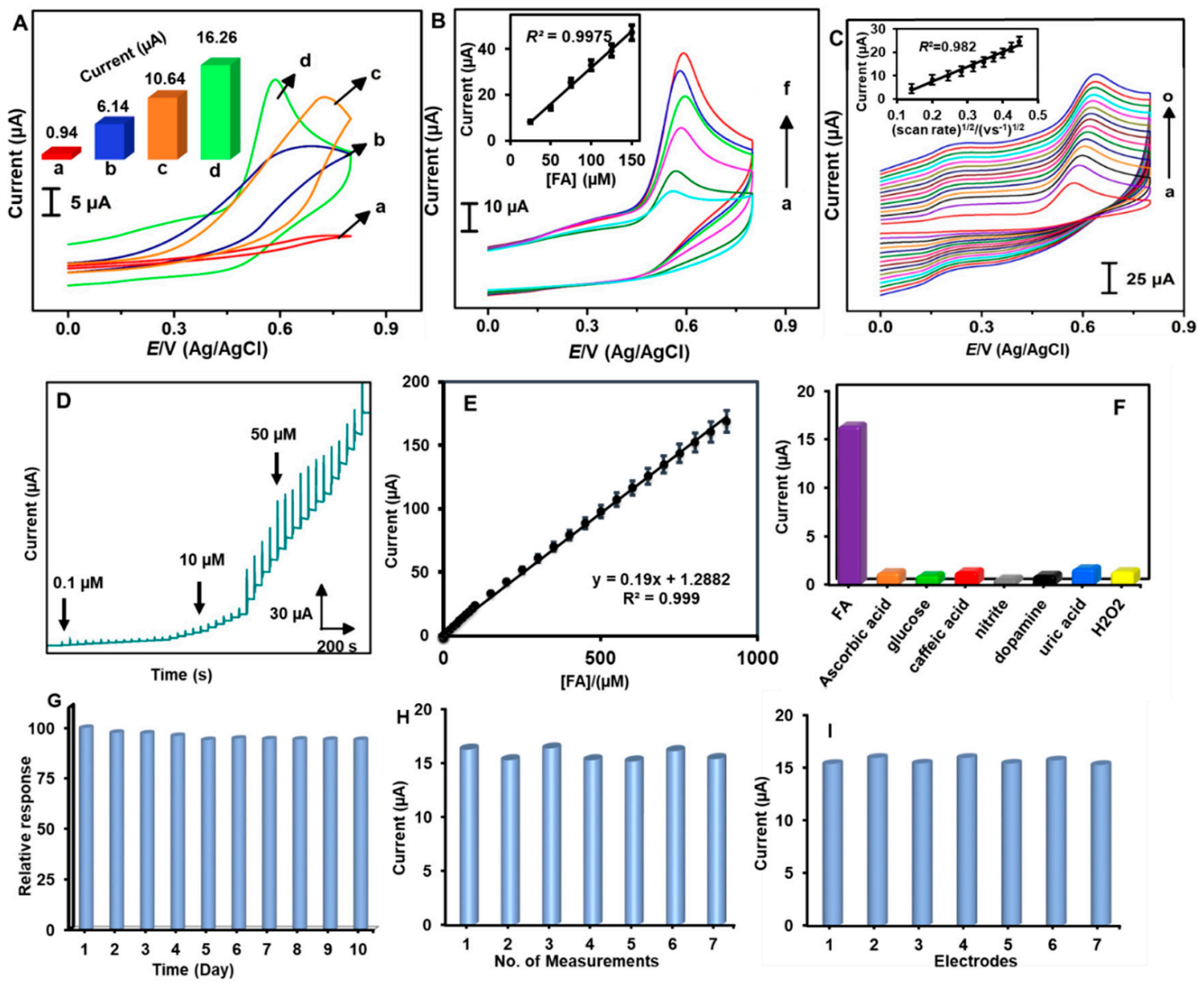

Figure 6. (A) CVs obtained at (a) unmodified GCE, (b) GCE/rGO/DA, (c) GCE/rGO/AuNPs, and (d) $\mathrm{GCE} / \mathrm{rGO} / \mathrm{PDA} / \mathrm{AuNPs}$ towards $50 \mu \mathrm{M}$ FA suspended in phosphate buffer ( $\mathrm{pH} 7.0$ ). Inset: plot of current versus electrodes. (B) CVs of GCE/rGO/PDA/AuNPs towards varied concentrations of FA ( $\mathrm{a}=25$, $\mathrm{b}=50, \mathrm{c}=75, \mathrm{~d}=100, \mathrm{e}=125, \mathrm{f}=150 \mu \mathrm{M}$ ) suspended in phosphate buffer ( $\mathrm{pH} 7.0$ ), inset: anodic peak current $/ \mu$ A versus $[\mathrm{FA}] / \mu \mathrm{M}$. (C) CVs obtained at GCE/rGO/PDA/AuNPs in phosphate buffer (pH 7.0) containing $50 \mu \mathrm{M}$ FA at different scan rates (a to j: 0.02 to $0.2 \mathrm{~V} \mathrm{~s}^{-1}$ ). Inset: FA reduction peak current versus (scan rate $)^{1 / 2}$. (D) Amperometric responses of GCE/rGO/PDA/AuNPs towards series of different FA concentrations injected in phosphate buffer ( $\mathrm{pH}$ 7.0) and (E) corresponding linear calibration plot, applied potential $=0.55 \mathrm{~V}$. (F) Amperometric responses of GCE/rGO/PDA/AuNPs toward $50 \mu \mathrm{M}$ FA and 10-fold higher concentration of other species. (G) FA sensing performance of GCE/rGO/PDA/AuNPs for 10 continuous days (stability test), $(\mathbf{H}) 7$ repeated measurements using a single electrode (repeatability test) and (I) reproducibility of 7 separate experiments using 7 independently fabricated electrodes. For stability, repeatability, and reproducibility, CVs were performed toward $50 \mu \mathrm{M}$ FA in a $0.1 \mathrm{M}$ phosphate buffer ( $\mathrm{pH} 7.0$ ), while FA oxidation peak current was used to plot the bar diagram. 
Table 3. Comparison of folic acid analytical parameters between rGO/PDA/AuNPs film and reported modifiers.

\begin{tabular}{|c|c|c|c|}
\hline Electrode & Linear Range $/ \mu \mathbf{M}$ & $\mathrm{LOD} / \mu \mathrm{M}$ & Ref. \\
\hline $\begin{array}{l}\text { Carbon paste electrode/Pt-Co } \\
\text { nanoparticles/2-(3,4-dihydroxyphenethyl) } \\
\text { isoindoline-1,3-dione }\end{array}$ & $2-550$ & 0.8 & [48] \\
\hline Methylene blue/rGO & $4-167$ & 0.5 & [49] \\
\hline $\mathrm{Fe}_{3} \mathrm{O}_{4}$ nanoparticles & $0.065-98$ & 0.002 & [36] \\
\hline B-doped polycrystalline diamond & $0.1-167$ & 0.03 & {$[50]$} \\
\hline $\mathrm{MoS}_{2} / \mathrm{rGO}$ & $0.01-100$ & 0.01 & [51] \\
\hline ferrocenedicarboxylic acid-MWCNTs & $4.6-152$ & 1.1 & [52] \\
\hline $\begin{array}{c}\text { Au nanoclusters-activated } \\
\text { graphene/MWCNT }\end{array}$ & $10-170$ & 0.09 & [53] \\
\hline $\mathrm{rGO} / \mathrm{PDA} / \mathrm{AuNPs}$ & $0.1-905$ & 0.025 & This work \\
\hline
\end{tabular}

Table 4. Determination of spiked FA in biological samples using GCE/rGO/PDA/AuNPs.

\begin{tabular}{ccccc}
\hline Samples & Added $/ \boldsymbol{\mu M}$ & Found $/ \boldsymbol{\mu M}$ & Recovery/\% & RSD */\% \\
\hline \multirow{2}{*}{ Human serum } & 5 & 4.76 & 95.2 & 2.58 \\
& 10 & 9.77 & 97.7 & 3.53 \\
\hline \multirow{2}{*}{ Human urine } & 5 & 4.85 & 97.0 & 2.63 \\
& 10 & 9.73 & 97.3 & 3.70 \\
\hline
\end{tabular}

* Relative Standard Deviation (RSD) of three individual measurements.

\section{Materials and Methods}

\subsection{Chemicals and Instrumentation}

Multi-walled CNTs (bundled $>95 \%$ ), graphite (powder, $<20 \mu \mathrm{m}$ ), dopamine, $\mathrm{HAuCl}_{4} \cdot 3 \mathrm{H}_{2} \mathrm{O}$ $(99.9 \%)$, chloramphenicol, folic acid, and all other chemicals were acquired from sigma-Aldrich, Taiwan and used as received. All chemical reagents were used as received without further purification. Deionized water from Millipore was used for the reagent preparation, and throughout the experiments. $\mathrm{Na}_{2} \mathrm{HPO}_{4} \cdot 12 \mathrm{H}_{2} \mathrm{O}$ and $\mathrm{NaH}_{2} \mathrm{PO}_{4} \cdot 2 \mathrm{H}_{2} \mathrm{O}$ were used to prepare $0.1 \mathrm{M}$ phosphate buffer (pH 7.0). Milk, powdered milk, and honey samples were purchased from a local supermarket, Taipei, Taiwan. Stock solution of CAP and FA were prepared in $0.1 \mathrm{M}$ phosphate buffer (pH 7.0).

The size and morphology of the as-prepared materials were examined by using scanning electron microscopy (SEM, Hitachi S-3000 H scanning electron microscope) and transmission electron microscopy (TEM, Hitachi H-600 TEM). Samples for SEM and TEM were prepared by dropping an aqueous dispersion of materials on Indium tin oxide (ITO) substrates and copper TEM grids respectively, and dried under ambient conditions. Energy-dispersive X-ray (EDX) spectra and mapping were recorded using HORIBA EMAX X-ACT (Sensor $+24 \mathrm{~V}=16 \mathrm{~W}$, resolution at $5.9 \mathrm{keV}$ ). The powder X-ray diffraction (XRD) analysis was performed on a XPERT-PRO (PANalytical B.V., The Netherlands) diffractometer using $\mathrm{Cu} K \alpha$ radiation $(k=1.54 \AA)$ to examine crystallinity of the nanomaterials. $\mathrm{X}$-ray photoelectron spectra (XPS) were obtained by using XPS, PerkinElmer PHI-5702.

\subsection{Synthesis of $C N T s / P D A / A u N P s$}

In a typical synthesis, first, functionalized CNTs were prepared by treating CNTs with acids. First, CNTs $\left(50 \mathrm{mg}\right.$ ) were suspended in a $100 \mathrm{~mL}$ mixture of $\mathrm{H}_{2} \mathrm{SO}_{4}$ and $\mathrm{HNO}_{3}$, ultrasonicated for $3 \mathrm{~h}$, washed $2 \times$ with deionized water (DI) water $(200 \mathrm{~mL}$ each) and $2 \times$ with ethanol $(200 \mathrm{~mL}$ each), freeze-dried, and re-dispersed in water $\left(1 \mathrm{mg} \mathrm{mL}^{-1}\right)$. About $20 \mathrm{~mL}$ aqueous solution of $1 \mathrm{mg} / \mathrm{mL}$ DA prepared in Tris buffer was then added to $25 \mathrm{~mL}$ of the functionalized CNTs $\left(f\right.$-CNTs). Subsequently, $\mathrm{HAuCl}_{4} \cdot 3 \mathrm{H}_{2} \mathrm{O}$ 
$(1 \mathrm{~mL}, 5 \mathrm{mM})$ was added and the entire mixture was stirred. Next, $\mathrm{pH}$ of the reaction mixture was adjusted to $\mathrm{pH} 9.0$ by adding $0.1 \mathrm{M} \mathrm{NaOH}$, and stirred for $15 \mathrm{~min}$. Subsequently, the reaction mixture was transferred into a microwave oven, equipped with a temperature-control condenser system and a stirrer. Microwave with effective power set at $200 \mathrm{~W}$ for a total irradiation time was applied for $5 \mathrm{~min}$ and the solution was stirred at $500 \mathrm{rpm}$ during irradiation. Finally, the CNTs/PDA/AuNPs nanocomposite was separated through centrifugation ( $4000 \mathrm{rpm}, 30 \mathrm{~min}$ ), washed $3 \times$ with DI water (50 mL each) and $2 \times$ with ethanol $(50 \mathrm{~mL}$ each), and freeze-dried.

\subsection{Synthesis of $r G O / P D A / A u N P s$}

First, graphite oxide was prepared from graphite by modified Hummers method. Then, it was exfoliated to $\mathrm{GO}$ in water via ultrasonic agitation for $2 \mathrm{~h}$. About $50 \mathrm{mg}$ of $\mathrm{DA}$ and $\mathrm{HAuCl}_{4} \cdot 3 \mathrm{H}_{2} \mathrm{O}(1 \mathrm{~mL}$, $5 \mathrm{mM}$ ) were added to the as-prepared GO $(50 \mathrm{~mL})$ and stirred for $15 \mathrm{~min}$. Next, $\mathrm{pH}$ of the mixture was adjusted to $\mathrm{pH} 9.0$ and stirred for $15 \mathrm{~min}$. Subsequently, the reaction mixture was transformed into a microwave oven and irradiated for $5 \mathrm{~min}$ along with stirring $(500 \mathrm{rpm})$. The nanocomposite was separated by centrifugation ( $4000 \mathrm{rpm}, 30 \mathrm{~min}$ ), washed $3 \times$ with DI water (50 mL each) and $2 \times$ with ethanol (50 $\mathrm{mL}$ each), and freeze-dried.

\subsection{Fabrication of CNTs/PDA/AuNPs and rGO/PDA/AuNPs Modified Glassy Carbon Electrodes (GCEs)}

$1 \mathrm{mg}$ of $\mathrm{CNTs} / \mathrm{PDA} / \mathrm{AuNPs}$ nanocomposite was re-dispersed in $1 \mathrm{~mL}$ water via ultrasonication for $10 \mathrm{~min} .5 \mu \mathrm{L}$ dispersion of $\mathrm{CNTs} / \mathrm{PDA} / \mathrm{AuNPs}$ was drop-casted on the pre-cleaned GCE and dried to yield GCE/CNTs/PDA/AuNPs. GCE/CNTs/AuNPs and GCE/CNTs/PDA were also prepared to execute control experiments. Similarly, GCE/rGO/PDA/AuNPs, GCE/rGO/AuNPs, and GCE/PDA/AuNPs were also fabricated.

\subsection{Electrochemical Experiments}

The electrochemical experiments were conducted in a conventional three-electrode system at room temperature with a potentiostat (CHI 621d workstation, USA). The nanocomposite-modified electrode, $\mathrm{Ag} / \mathrm{AgCl}$ (saturated $\mathrm{KCl}$ ), and Pt wire were used as working (area $0.071 \mathrm{~cm}^{2}$ ), reference, and counter electrodes, respectively. $0.1 \mathrm{M}$ phosphate buffer ( $\mathrm{pH}$ 7.0) was used as a supporting electrolyte for electrochemical studies. Before being modified with nanomaterials, the surface of the GCE was polished with $0.5 \mu \mathrm{m}$ alumina slurry using a Buelher polishing pad, then ultrasonicated in ethanol and water for $5 \mathrm{~min}$ and dried under ambient conditions. The electrolyte solutions were deoxygenated with nitrogen for $10 \mathrm{~min}$ before each electrochemical test.

\subsection{Preparation of Real Samples}

The practical applicability of the method has been demonstrated in milk, powdered milk, and honey samples. The samples were prepared by following our previous procedures [28]. Powdered milk ( $1 \mathrm{~g}$ ) was dissolved in $10 \mathrm{~mL}$ phosphate buffer ( $\mathrm{pH}$ 7.0). Then, known amounts of CAP were spiked and the resulting solution was transferred to a microcentrifuge tube. Subsequently, $250 \mu \mathrm{L}$ of perchloric acid $(0.25 \mathrm{M})$ was added and the entire solution was stirred for $15 \mathrm{~min}$ and then centrifuged ( $3000 \times g, 10 \mathrm{~min})$. The centrifugate was filtered, and $\mathrm{pH}$ was adjusted to 7 and used for real sample analysis of CAP. To prepare the honey sample, $1.0 \mathrm{~g}$ honey was dissolved in $10 \mathrm{~mL}$ phosphate buffer, transferred to a microcentrifuge tube, and spiked with CAP. About $4 \mathrm{~mL}$ of ethyl acetate was added and the solution was mixed completely on a vortex. The solution was centrifuged $(3000 \times g, 10 \mathrm{~min})$ and filtered. The filtrate was adjusted to $\mathrm{pH} 7$ before being used for electrochemical analysis. To prepare the milk sample, $1 \mathrm{~mL}$ of milk in $5 \mathrm{~mL}$ phosphate buffer was spiked with appropriate amounts of CAP and used for studies. With his permission and approval from the organizational ethical clearance committee for human studies, human blood was obtained from a healthy volunteer. Human serum was extracted from blood by following the existing literature published elsewhere. 


\section{Conclusions}

In summary, an efficient, quick, green, and benign method for the synthesis of C/PDA/AuNPs nanocomposites has been developed. A series of morphological, elemental, spectral, and electrochemical characterizations ensures the successful formation of nanocomposites. Nano-sized spherical-shaped AuNPs in the size range of $50-100 \mathrm{~nm}$, and thin rGO sheets at nanoscale were witnessed. The CNTs/ PDA/AuNPs-modified electrode was found to be highly efficient for CAP sensing with a detection limit of $36 \mathrm{nM}$, and the method is successful in quantifying CAP spiked in milk, powdered milk. and honey samples (recoveries $95.0 \%-98.4 \%$ ), thus it holds great promise in food safety appliances. The rGO/PDA/AuNPs nanocomposite is an excellent electrocatalyst for FA oxidation and it can be used to fabricate a rapid, sensitive sensor for FA in biological samples. The linear range for the FA sensor was 0.1-905 $\mu \mathrm{M}$ and the detection limit was $25 \mathrm{nM}$. The synthetic process described herein can be extended to produce multifunctional nanocomposites by replacing PDA with other polymers (water-soluble polymers) and AuNPs with other metal nanoparticles.

Author Contributions: Conceptualization, V.M.; methodology, T.S.T.B.; software, M.V. and T.S.T.B.; validation, M.V., T.S.T.B. and S.-T.H.; formal analysis, M.V.; investigation, M.V.; resources, S.-T.H.; data curation, M.V. and T.S.T.B.; writing—original draft preparation, M.V. and T.S.T.B.; writing—review and editing, M.V.; visualization, M.V.; supervision, M.V. and S.-T.H.; project administration, M.V. and S.-T.H.; funding acquisition, M.V. and S.T.H. All authors have read and agreed to the published version of the manuscript.

Funding: This research was funded by the Ministry of Science and Technology (MOST), Taiwan, grant numbers 107-2113-M-027-007 and 108-2221-E-027-063.

Conflicts of Interest: The authors declare no conflict of interest.

\section{References}

1. Yang, W.; Ratinac, K.R.; Ringer, S.P.; Thordarson, P.; Gooding, J.J.; Braet, F. Carbon nanomaterials in biosensors: Should you use nanotubes or graphene? Angew. Chem. Int. Ed. 2010, 49, 2114-2138. [CrossRef] [PubMed]

2. Khan, A.H.; Ghosh, S.; Pradhan, B.; Dalui, A.; Shrestha, L.K.; Acharya, S.; Ariga, K. Two-dimensional (2D) nanomaterials towards electrochemical nanoarchitectonics in energy-related applications. Bull. Chem. Soc. Jpn. 2017, 90, 627-648. [CrossRef]

3. Song, Y.; Luo, Y.; Zhu, C.; Li, H.; Du, D.; Lin, Y. Recent advances in electrochemical biosensors based on graphene two-dimensional nanomaterials. Biosens. Bioelectron. 2016, 76, 195-212. [CrossRef] [PubMed]

4. Zhang, X.; Hou, L.; Samori, P. Coupling carbon nanomaterials with photochromic molecules for the generation of optically responsive materials. Nat. Commun. 2016, 7, 11118. [CrossRef] [PubMed]

5. Mani, V.; Govindasamy, M.; Chen, S.-M.; Karthik, R.; Huang, S.-T. Determination of dopamine using a glassy carbon electrode modified with a graphene and carbon nanotube hybrid decorated with molybdenum disulfide flowers. Microchim. Acta 2016, 183, 2267-2275. [CrossRef]

6. Yan, Q.-L.; Gozin, M.; Zhao, F.-Q.; Cohen, A.; Pang, S.-P. Highly energetic compositions based on functionalized carbon nanomaterials. Nanoscale 2016, 8, 4799-4851. [CrossRef]

7. Punetha, V.D.; Rana, S.; Yoo, H.J.; Chaurasia, A.; McLeskey, J.T., Jr.; Ramasamy, M.S.; Sahoo, N.G.; Cho, J.W. Functionalization of carbon nanomaterials for advanced polymer nanocomposites: A comparison study between CNT and graphene. Prog. Polym. Sci. 2017, 67, 1-47. [CrossRef]

8. Mani, V.; Govindasamy, M.; Chen, S.-M.; Chen, T.-W.; Kumar, A.S.; Huang, S.-T. Core-shell heterostructured multiwalled carbon nanotubes@reduced graphene oxide nanoribbons/chitosan, a robust nanobiocomposite for enzymatic biosensing of hydrogen peroxide and nitrite. Sci. Rep. 2017, 7, 11910. [CrossRef]

9. Zhang, B.-T.; Zheng, X.; Li, H.-F.; Lin, J.-M. Application of carbon-based nanomaterials in sample preparation: A review. Anal. Chim. Acta 2013, 784, 1-17. [CrossRef]

10. Komane, P.P.; Kumar, P.; Choonara, Y.E.; Pillay, V. Functionalized, vertically super-aligned multiwalled carbon nanotubes for potential biomedical applications. Int. J. Mol. Sci. 2020, 21, 2276. [CrossRef]

11. Surya, S.G.; Majhi, S.M.; Agarwal, D.K.; Lahcen, A.A.; Yuvaraja, S.; Chappanda, K.N.; Salama, K.N. A label-free aptasensor FET based on Au nanoparticle decorated $\mathrm{Co}_{3} \mathrm{O}_{4}$ nanorods and a SWCNT layer for detection of cardiac troponin T protein. J. Mat. Chem. B 2020, 8, 18-26. [CrossRef] 
12. Barsan, M.M.; Ghica, M.E.; Brett, C.M. Electrochemical sensors and biosensors based on redox polymer/carbon nanotube modified electrodes: A review. Anal. Chim. Acta 2015, 881, 1-23. [CrossRef]

13. Ai, L.; Tian, T.; Jiang, J. Ultrathin graphene layers encapsulating nickel nanoparticles derived metal-organic frameworks for highly efficient electrocatalytic hydrogen and oxygen evolution reactions. ACS Sustain. Chem. Eng. 2017, 5, 4771-4777. [CrossRef]

14. Mani, V.; Chen, S.-M.; Lou, B.-S. Three dimensional graphene oxide-carbon nanotubes and graphene-carbon nanotubes hybrids. Int. J. Electrochem. Sci. 2013, 8, 60.

15. Liu, Y.; Ai, K.; Lu, L. Polydopamine and its derivative materials: Synthesis and promising applications in energy, environmental, and biomedical fields. Chem. Rev. 2014, 114, 5057-5115. [CrossRef] [PubMed]

16. Liang, J.; Xiao, C.; Chen, X.; Gao, R.; Ding, S. Porous $\gamma-\mathrm{Fe}_{2} \mathrm{O}_{3}$ spheres coated with N-doped carbon from polydopamine as Li-ion battery anode materials. Nanotechnology 2016, 27, 215403. [CrossRef]

17. Luo, J.; Jiang, S.; Liu, X. Efficient one-pot synthesis of mussel-inspired molecularly imprinted polymer coated graphene for protein-specific recognition and fast separation. J. Phy. Chem. C 2013, 117, 18448-18456. [CrossRef]

18. Devasenathipathy, R.; Mani, V.; Chen, S.-M. Highly selective amperometric sensor for the trace level detection of hydrazine at bismuth nanoparticles decorated graphene nanosheets modified electrode. Talanta 2014, 124, 43-51. [CrossRef]

19. Ponnusamy, V.K.; Mani, V.; Chen, S.-M.; Huang, W.-T.; Jen, J.-F. Rapid microwave assisted synthesis of graphene nanosheets/polyethyleneimine/gold nanoparticle composite and its application to the selective electrochemical determination of dopamine. Talanta 2014, 120, 148-157. [CrossRef]

20. Rao, C.R.; Kulkarni, G.U.; Thomas, P.J.; Edwards, P.P. Metal nanoparticles and their assemblies. Chem. Soc. Rev. 2000, 29, 27-35. [CrossRef]

21. Kim, Y.-K.; Min, D.-H. Preparation of the hybrid film of poly (allylamine hydrochloride)-functionalized graphene oxide and gold nanoparticle and its application for laser-induced desorption/ionization of small molecules. Langmuir 2012, 28, 4453-4458. [CrossRef] [PubMed]

22. Wang, Y.; Xiong, Y.; Qu, J.; Qu, J.; Li, S. Selective sensing of hydroquinone and catechol based on multiwalled carbon nanotubes/polydopamine/gold nanoparticles composites. Sens. Actuators B 2016, 223, 501-508. [CrossRef]

23. Huang, K.-J.; Wang, L.; Wang, H.-B.; Gan, T.; Wu, Y.-Y.; Li, J.; Liu, Y.-M. Electrochemical biosensor based on silver nanoparticles-polydopamine-graphene nanocomposite for sensitive determination of adenine and guanine. Talanta 2013, 114, 43-48. [CrossRef] [PubMed]

24. Huang, K.-J.; Liu, Y.-J.; Wang, H.-B.; Wang, Y.-Y. A sensitive electrochemical DNA biosensor based on silver nanoparticles-polydopamine@ graphene composite. Electrochim. Acta 2014, 118, 130-137. [CrossRef]

25. Liu, Y.; Han, Y.; Chen, R.; Zhang, H.; Liu, S.; Liang, F. In situ immobilization of copper nanoparticles on polydopamine coated graphene oxide for $\mathrm{H}_{2} \mathrm{O}_{2}$ determination. PLoS ONE 2016, 11, e0157926. [CrossRef]

26. Zhang, S.; Huang, N.; Lu, Q.; Liu, M.; Li, H.; Zhang, Y.; Yao, S. A double signal electrochemical human immunoglobulin $\mathrm{G}$ immunosensor based on gold nanoparticles-polydopamine functionalized reduced graphene oxide as a sensor platform and AgNPs/carbon nanocomposite as signal probe and catalytic substrate. Biosens. Bioelectron. 2016, 77, 1078-1085. [CrossRef]

27. Rajaji, U.; Manavalan, S.; Chen, S.-M.; Govindasamy, M.; Chen, T.-W.; Maiyalagan, T. Microwave-assisted synthesis of europium(III) oxide decorated reduced graphene oxide nanocomposite for detection of chloramphenicol in food samples. Compos. Part B 2019, 161, 29-36. [CrossRef]

28. Wang, M.-H.; Gu, J.-A.; Mani, V.; Wu, Y.-C.; Lin, Y.-J.; Chia, Y.-M.; Huang, S.-T. A rapid fluorescence detecting platform: Applicable to sense carnitine and chloramphenicol in food samples. RSC Adv. 2014, 4, 64112-64118. [CrossRef]

29. Alibolandi, M.; Hadizadeh, F.; Vajhedin, F.; Abnous, K.; Ramezani, M. Design and fabrication of an aptasensor for chloramphenicol based on energy transfer of CdTe quantum dots to graphene oxide sheet. Mater. Sci. Eng. C 2015, 48, 611-619. [CrossRef]

30. Borowiec, J.; Wang, R.; Zhu, L.; Zhang, J. Synthesis of nitrogen-doped graphene nanosheets decorated with gold nanoparticles as an improved sensor for electrochemical determination of chloramphenicol. Electrochim. Acta 2013, 99, 138-144. [CrossRef]

31. Rajaji, U.; Muthumariappan, A.; Chen, S.-M.; Chen, T.-W.; Tseng, T.-W.; Wang, K.; Qi, D.; Jiang, J. Facile sonochemical synthesis of porous and hierarchical manganese(III) oxide tiny nanostructures for super sensitive electrocatalytic detection of antibiotic (chloramphenicol) in fresh milk. Ultrason. Sonochem. 2019, 58, 104648. [CrossRef] [PubMed] 
32. Zhu, C.; Yang, G.; Li, H.; Du, D.; Lin, Y. Electrochemical sensors and biosensors based on nanomaterials and nanostructures. Anal. Chem. 2015, 87, 230-249. [CrossRef] [PubMed]

33. Akbar, S.; Anwar, A.; Kanwal, Q. Electrochemical determination of folic acid: A short review. Anal. Biochem. 2016, 510, 98-105. [CrossRef] [PubMed]

34. Elumalai, S.; Mani, V.; Jeromiyas, N.; Ponnusamy, V.K.; Yoshimura, M. A composite film prepared from titanium carbide $\mathrm{Ti}_{3} \mathrm{C}_{2} \mathrm{~T}_{\mathrm{x}}$ (MXene) and gold nanoparticles for voltammetric determination of uric acid and folic acid. Microchim. Acta 2020, 187, 33. [CrossRef] [PubMed]

35. Kalimuthu, P.; John, S.A. Selective electrochemical sensor for folic acid at physiological pH using ultrathin electropolymerized film of functionalized thiadiazole modified glassy carbon electrode. Biosens. Bioelectron. 2009, 24, 3575-3580. [CrossRef] [PubMed]

36. Kingsley, M.P.; Desai, P.B.; Srivastava, A.K. Simultaneous electro-catalytic oxidative determination of ascorbic acid and folic acid using $\mathrm{Fe}_{3} \mathrm{O}_{4}$ nanoparticles modified carbon paste electrode. J. Electroanal. Chem. 2015, 741,71-79. [CrossRef]

37. Mani, V.; Umamaheswari, R.; Chen, S.-M.; Govindasamy, M.; Su, C.; Sathiyan, A.; Merlin, J.P.; Keerthi, M. Highly sensitive determination of folic acid using graphene oxide nanoribbon film modified screen printed carbon electrode. Int. J. Electrochem. Sci. 2017, 12, 475-484. [CrossRef]

38. Govindasamy, M.; Manavalan, S.; Chen, S.M.; Rajaji, U.; Chen, T.W.; Al-Hemaid, F.M.A.; Ali, M.A.; Elshikh, M.S. Determination of neurotransmitter in biological and drug samples using gold nanorods decorated f-MWCNTs modified electrode. J. Electrochem. Soc. 2018, 165, B370-B377. [CrossRef]

39. Devasenathipathy, R.; Mani, V.; Chen, S.-M.; Viswanath, B.; Vasantha, V.S.; Govindasamy, M. Electrodeposition of gold nanoparticles on a pectin scaffold and its electrocatalytic application in the selective determination of dopamine. RSC Adv. 2014, 4, 55900-55907. [CrossRef]

40. Mani, V.; Govindasamy, M.; Chen, S.-M.; Subramani, B.; Sathiyan, A.; Merlin, J.P. Determination of folic acid using graphene/molybdenum disulfide nanosheets/gold nanoparticles ternary composite. Int. J. Electrochem. Sci. 2017, 12, e267. [CrossRef]

41. Govindasamy, M.; Chen, S.-M.; Mani, V.; Devasenathipathy, R.; Umamaheswari, R.; Santhanaraj, K.J.; Sathiyan, A. Molybdenum disulfide nanosheets coated multiwalled carbon nanotubes composite for highly sensitive determination of chloramphenicol in food samples milk, honey and powdered milk. J. Colloid Interface Sci. 2017, 485, 129-136. [CrossRef] [PubMed]

42. Zhang, X.; Zhang, Y.-C.; Zhang, J.-W. A highly selective electrochemical sensor for chloramphenicol based on three-dimensional reduced graphene oxide architectures. Talanta 2016, 161, 567-573. [CrossRef] [PubMed]

43. Yang, R.; Zhao, J.; Chen, M.; Yang, T.; Luo, S.; Jiao, K. Electrocatalytic determination of chloramphenicol based on molybdenum disulfide nanosheets and self-doped polyaniline. Talanta 2015, 131, 619-623. [CrossRef] [PubMed]

44. Jakubec, P.; Urbanová, V.; Medříková, Z.; Zbořil, R. Advanced sensing of antibiotics with magnetic gold nanocomposite: Electrochemical detection of chloramphenicol. Chem. Eur. J. 2016, 22, 14279-14284. [CrossRef] [PubMed]

45. Karthik, R.; Govindasamy, M.; Chen, S.-M.; Mani, V.; Lou, B.-S.; Devasenathipathy, R.; Hou, Y.-S.; Elangovan, A. Green synthesized gold nanoparticles decorated graphene oxide for sensitive determination of chloramphenicol in milk, powdered milk, honey and eye drops. J. Colloid Interface Sci. 2016, 475, 46-56. [CrossRef]

46. Agüı, L.; Guzmán, A.; Yáñez-Sedeño, P.; Pingarrón, J. Voltammetric determination of chloramphenicol in milk at electrochemically activated carbon fibre microelectrodes. Anal. Chim. Acta 2002, 461, 65-73. [CrossRef]

47. Kong, F.-Y.; Chen, T.-T.; Wang, J.-Y.; Fang, H.-L.; Fan, D.-H.; Wang, W. UV-assisted synthesis of tetrapods-like titanium nitride-reduced graphene oxide nanohybrids for electrochemical determination of chloramphenicol. Sens. Actuators B 2016, 225, 298-304. [CrossRef]

48. Karimi-Maleh, H.; Hatami, M.; Moradi, R.; Khalilzadeh, M.A.; Amiri, S.; Sadeghifar, H. Synergic effect of Pt-Co nanoparticles and a dopamine derivative in a nanostructured electrochemical sensor for simultaneous determination of $\mathrm{N}$-acetylcysteine, paracetamol and folic acid. Microchim. Acta 2016, 183, 2957-2964. [CrossRef]

49. Zhang, D.; Ouyang, X.; Ma, W.; Li, L.; Zhang, Y. Voltammetric determination of folic acid using adsorption of methylene blue onto electrodeposited of reduced graphene oxide film modified glassy carbon electrode. Electroanalysis 2016, 28, 312-319. [CrossRef] 
50. Cinková, K.; Švorc, L'; Šatkovská, P.; Vojs, M.; Michniak, P.; Marton, M. Simple and rapid quantification of folic acid in pharmaceutical tablets using a cathodically pretreated highly boron-doped polycrystalline diamond electrode. Anal. Lett. 2016, 49, 107-121. [CrossRef]

51. Chekin, F.; Teodorescu, F.; Coffinier, Y.; Pan, G.-H.; Barras, A.; Boukherroub, R.; Szunerits, S. MoS $2 /$ reduced $^{2}$ graphene oxide as active hybrid material for the electrochemical detection of folic acid in human serum. Biosens. Bioelectron. 2016, 85, 807-813. [CrossRef] [PubMed]

52. Ensafi, A.A.; Karimi-Maleh, H. Modified multiwall carbon nanotubes paste electrode as a sensor for simultaneous determination of 6-thioguanine and folic acid using ferrocenedicarboxylic acid as a mediator. J. Electroanal. Chem. 2010, 640, 75-83. [CrossRef]

53. Abdelwahab, A.A.; Shim, Y.-B. Simultaneous determination of ascorbic acid, dopamine, uric acid and folic acid based on activated graphene/MWCNT nanocomposite loaded Au nanoclusters. Sens. Actuators B 2015, 221, 659-665. [CrossRef]

(C) 2020 by the authors. Licensee MDPI, Basel, Switzerland. This article is an open access article distributed under the terms and conditions of the Creative Commons Attribution (CC BY) license (http://creativecommons.org/licenses/by/4.0/). 